\title{
DHEA, a Neurosteroid, Decreases Cocaine Self-Administration and Reinstatement of Cocaine-Seeking Behavior in Rats
}

\author{
Ravid Doron', Lilach Fridman', Iris Gispan-Herman', Rachel Maayan², Abraham Weizman ${ }^{2,3}$ \\ and Gal Yadid*, I \\ 'Faculty of Life Sciences and The Leslie and Susan Gonda (Goldschmied) Multidisciplinary Brain Research Center, Bar-Ilan University, Ramat-Gan, \\ Israel; ${ }^{2}$ Biological Psychiatry, Felsenstein Medical Research Center, Beilinson Campus, Petah-Tikva, Israel; ${ }^{3}$ Sackler Faculty of Medicine, Tel-Aviv \\ University, Tel-Aviv, Israel
}

\begin{abstract}
Dehydroepiandrosterone (DHEA), which can act as a potential antidepressant in both animals and humans, appears to lower distress involved with cocaine withdrawal. In fact, a role for neurosteroids in modulation of substance-seeking behavior is becoming increasingly clear. Therefore, we tested the effects of DHEA on the self-administration of cocaine $(\mathrm{I} \mathrm{mg} / \mathrm{kg} / \mathrm{infusion})$ by rats. At maintenance, a relatively low dose of exogenous DHEA ( $2 \mathrm{mg} / \mathrm{kg}$; i.p.) attenuated cocaine self-administration after several days of chronic treatment. More than 2 weeks ( 19 days) of daily DHEA injections were required to decrease the cocaine-seeking behavior of rats to less than $20 \%$ of their maintenance levels. DHEA does not seem to decrease cocaine self-administration by increasing the reinforcing properties of the drug, as indicated by a cocaine dose-response determination. After being subjected to extinction conditions in the presence of DHEA, rats demonstrated a minimal response to acute exposure to cocaine $(10 \mathrm{mg} / \mathrm{kg})$, which indicated a protective effect of DHEA on relapse to cocaine usage. Our results suggest a potential role for the neurosteroid DHEA in controlling cocaine-seeking behavior, by reducing both the desire for cocaine usage and the incidence of relapse.

Neuropsychopharmacology (2006) 3 I, 2231-2236. doi:10.1038/sj.npp. I30 I0 I3; published online 18 January 2006
\end{abstract}

Keywords: cocaine addiction; dehydroepiandrosterone; self-administration; neurosteroid; reinforcement; withdrawal

\section{INTRODUCTION}

Effective treatments for cocaine addiction are not yet available (Soares et al, 2003); Stephen and Jonathan, 1998). Herein, the effects of the neurosteroid DHEA on self-administration of cocaine and reinstatement of cocaineseeking behavior in rats were examined with the goal of facilitating and developing an effective treatment for cocaine addiction.

Effects of steroid hormones on the nervous system are not limited to transcriptional regulation through interaction with nuclear receptors. Rapid, nongenomic and stereospecific steroid actions are also transmitted via specific membrane receptors, such as $\gamma$-aminobutyric-acid-type A $\left(\mathrm{GABA}_{\mathrm{A}}\right)$, ionotrophic glutamate, and sigma receptors. This type of rapid neuronal regulation is due to both the

\footnotetext{
*Correspondence: Dr G Yadid, Department of Life Sciences, Bar-llan University, Ramat-Gan 52900, Israel, Tel: +972 3 531 8123, Fax: +972 3535 1824, E-mail: yadidg@mail.biu.ac.il

Received 10 August 2005; revised 8 November 2005; accepted 9 November 2005

Online publication: 22 November 2005 at http://www.acnp.org/ citations/Npp I | 2205050499/default.pdf
}

action of gonadal steroids on the brain and synthesis of neurosteroids within the nervous system (Falkenstein et al, 2000; Jung-Testas et al, 1989).

Neurosteroids, which are synthesized from cholesterol, include $3 \alpha$-hydroxy-compounds (eg, pregnenolone, DHEA, and their sulfate derivatives) and metabolites of progesterone (eg, $3 \alpha$-hydroxy-5 $\alpha$-pregnan-20-one, also known as allopregnanolone) (Corpechot et al, 1993). Controversy surrounds the potential use of neuroactive steroids to modulate the effects of substances of abuse. For example, allopregnanolone and pregnanolone attenuate convulsant and sensitizing properties of cocaine in mice (Kaminski et al, 2003), whereas synthetically derived neuroactive steroids attenuate cocaine-induced sucrose intake in rats, but not cocaine-induced hyperactivity in mice (Vanover et al, 2000). Furthermore, none of these steroids alone induced conditioned place preference (CPP). However, during conditioning with cocaine, pretreatment with DHEA or pregnenolone increased the conditioned score, while pretreatment with either progesterone or a $5 \alpha$-reductase inhibitor blocked acquisition of cocaine-induced CPP (Romieu et al, 2003). Chronic, but not acute treatment with the neurosteroids, allopregnanolone $(0.5 \mathrm{mg} / \mathrm{kg})$, 
pregnenolone sulfate ( 2 and $5 \mathrm{mg} / \mathrm{kg}$ ), or DHEA sulfate (DHEA-S; 2 and $5 \mathrm{mg} / \mathrm{kg}$ ) prevents development of morphine tolerance and dependence and relieves withdrawal effects (Reddy and Kulkarni, 1997).

In humans, levels of DHEA and DHEA-S were recently shown to be altered during addiction to substances of abuse. Following discontinuation (1-3 weeks) of cocaine in hospitalized chronic cocaine users, plasma levels of cortisol were highest at the beginning of abstinence and then subsequently decreased, whereas levels of DHEA-S were low at the beginning and increased later (Buydens-Branchey et al, 2002). Lingering neuroendocrine perturbations were suggested to persist after discontinuation of cocaine use in addicts. In another study of cocaine abusers (3 weeks of in-hospital therapy for cocaine dependence and 10 weeks follow up), significantly lower levels of DHEA-S were observed in abusers that relapsed (Shoptaw et al, 2004; Wilkins et al, 1997). A connection between levels of DHEA-S and profile of mood states suggests that increased circulating DHEA-S levels may provide enhanced CNS resiliency during withdrawal by lowering distressed mood levels (Wilkins et al, 2005). However, this result is hard to accept, as it has been shown that preliminary treatment with DHEA (albeit at high doses) of cocaine addicts does not decrease cocaine usage (Shoptaw et al, 2004). Therefore, we tested the effects of DHEA on cocaine intake and reinstatement in a controlled experimental study using the self-administration paradigm in rats.

\section{MATERIALS AND METHODS}

\section{Subjects}

Male Sprague-Dawley rats (250-280 g; obtained from the Animal Breeding Center of Bar-Ilan University) were maintained on a 12-12 h light-dark cycle with free access to food and water. Catheters were implanted under anesthesia (chloral hydrate, $400 \mathrm{mg} / \mathrm{kg}$, i.p.; Merck, Germany) into the jugular vein of some rats as described previously (Roth-Deri et al, 2003). All experimental procedures were approved by the Animal Care and Use Committee of the University and were performed in accordance with the guidelines of the National Institute of Health.

\section{Administration of DHEA}

DHEA (Sigma Chemicals; St Louis, MO) was dissolved in 1-2 drops of DMSO and then diluted to $1 \mathrm{mg} / \mathrm{ml}$ of saline (final DMSO concentration was 1\%). Depending on the experimental protocol, rats were injected i.p. with DHEA $(2 \mathrm{mg} / \mathrm{kg}$ ) or vehicle (saline containing $1 \%$ of DMSO), $90 \mathrm{~min}$ prior to exposure to the operant chamber. According to a report by Wilkins et al (2005), cocaine addicts that had a two-fold increase in plasma DHEA-S levels compared to other addicts were less prone to relapse. Based on prior evaluation of the effect of DHEA injections on DHEA-S plasma levels in rat, we found that the optimal DHEA dose to achieve a two-fold increase in DHEA-S plasma levels was $2 \mathrm{mg} / \mathrm{kg}(2.3 \pm 0.4 \mathrm{ng} / \mathrm{ml}$ in cocaine self-administrating rats, vs $5.2 \pm 1.2 \mathrm{ng} / \mathrm{ml}$ in cocaine self-administrating rats treated concomitantly with $2 \mathrm{mg} / \mathrm{kg}$ DHEA; $n=15, p<0.05)$.

\section{Intravenous Catheterization}

The rats were implanted with intravenous silastic catheters (Dow Corning, Midland, MI) into the right jugular vein (Roth-Deri et al, 2003). The catheter was secured to the vein with silk sutures and was passed subcutaneously to the top of the skull where it exited into a connector (a modified 22 gauge cannula; Plastics One, Roanoke, VA) mounted to the skull with MX-80 screws (Small Parts, Inc., Miami Lakes, FL) and dental cement (Yates \& Bird, Chicago, IL). Catheter potency was tested daily by injecting sterile saline.

\section{Cocaine Self-Administration}

Rats $(n=42)$ were trained to self-administer cocaine as previously described (Roth-Deri et al, 2003). Briefly, 5 days after catheterization, rats were transferred to operant conditioning chambers (Med-Associates, Inc.; St Albans, Vermont) for $1 \mathrm{~h}$ daily until stable maintenance levels were attained (at least 3 days of 15-25 lever presses for cocaine reinforcement; $<20 \%$ deviation from the mean), during their dark cycle, and were allowed to self-administer cocaine i.v. $(0.13 \mathrm{ml} /$ infusion; $1.0 \mathrm{mg} / \mathrm{kg} / 20 \mathrm{~s}$; obtained from the National Institute on Drug Abuse, Research Technology Branch, Rockville, MD) via a lever press under an FR-1 schedule of reinforcement. During the infusion, a light located above the active lever was lit for $20 \mathrm{~s}$. During the $20 \mathrm{~s}$ intervals of cocaine infusion, active lever presses were recorded, but no additional cocaine reinforcement was provided. The number of cocaine infusions was limited to $15 / h$ to minimize cocaine overdose. Presses on the inactive lever were recorded, but did not activate the infusion pump.

\section{Sucrose Self-Administration}

Rats $(n=10)$ were trained to self-administer sucrose $(10 \%$ sucrose solution; $0.13 \mathrm{ml} /$ infusion) delivered into a liquid drop receptacle for oral consumption (ENV-200R3AM, Med-Associates, Inc.). Rats were daily transferred into the operant conditioning chambers (Med-Associates, Inc.; St Albans, Vermont) for 30 min sessions, during their dark cycle. The operant chambers and reinforcement schedule were the same as those used for cocaine self-administration. The number of rewards earned was limited to 50/session. The limitation was imposed because, as rats find sucrose to be highly palatable, they will self-administer at rates high enough to empty syringes during the sessions if given unlimited access. Rats were returned to home cages at the end of the daily session.

\section{Effect of DHEA Treatment on Maintenance of Cocaine Self-Administration}

Rats were allowed to self-administer cocaine $(1 \mathrm{mg} / \mathrm{kg} /$ $0.13 \mathrm{ml} /$ lever press) until stable maintenance levels were attained. On the following days, rats were subjected to DHEA $(n=10)$ injections $(2 \mathrm{mg} / \mathrm{kg}$ i.p. $90 \mathrm{~min}$ prior to placement in the operant chambers) on a daily basis until lever-pressing behavior resembled extinguished values $(<6$ responses/h). When the rats pressing on the active lever decreased to $<6$ responses/h $(<20 \%$ deviation from the mean) for at least 3 consecutive days, it was assumed to be 
nonreinforced by cocaine. A control group at maintenance $(n=13)$ was treated with vehicle using the same procedure. Active lever responses, reinforcements, and inactive lever responses were recorded.

DHEA-treated rats that have met the nonreinforced criterion and rats in the control group that were at maintenance were placed in the conditioning chamber and allowed to self-administer either a lower dose of cocaine $(0.5 \mathrm{mg} / \mathrm{kg} / \mathrm{lever}$ press $)$ or no cocaine $(0 \mathrm{mg} / \mathrm{kg} / \mathrm{lever}$ press $)$. Active and inactive lever responses were recorded. This test was conducted to assess the possibility that DHEA treatment increases sensitivity to cocaine.

\section{Effect of DHEA Treatment on Reinstatement to Cocaine-Seeking Behavior}

A separate group of rats were trained to self-administer cocaine $(1 \mathrm{mg} / \mathrm{kg} / 0.13 \mathrm{ml} / \mathrm{lever}$ press $)$ until stable maintenance levels were attained. On the following days, rats were exposed to cocaine extinction phase. The conditions during the extinction phase were the same as during training with the exception that the cocaine syringes were removed, and that 90 min prior to placement in the operant chambers rats were injected either with DHEA (2 mg/kg i.p.) $(n=8)$ or with vehicle (same volume) $(n=7)$. Rats whose lever presses decreased to five or less per session for at least 3 consecutive days received a priming injection of cocaine $(10 \mathrm{mg} / \mathrm{kg}$, i.p.), $10 \mathrm{~min}$ before placement in the selfadministration chambers. In order to verify that the injection did not affect the number of lever presses, both groups of rats were i.p. injected with saline, $10 \mathrm{~min}$ before placement in the self-administration chambers, for 2 consecutive days before cocaine priming. Active lever responses, reinforcements, and inactive lever responses were recorded.

\section{Effect of DHEA Treatment on The Maintenance of Sucrose Self-Administration}

Rats were allowed to self-administer sucrose (10\% sucrose solution/0.13 ml/lever press) until stable maintenance levels were attained (at least 3 days of stable lever presses for sucrose reinforcement; $<20 \%$ deviation from the mean). On the following 19 days, rats were subjected to daily DHEA $(n=6)$ or vehicle $(n=4)$ injections $(2 \mathrm{mg} / \mathrm{kg}$ i.p. $), 90 \mathrm{~min}$ prior to placement in the operant chambers. Active lever responses, reinforcements, and inactive lever responses were recorded. This experiment was used as a control for assessing DHEA effects on operant behavior.

\section{Statistical Analysis}

A one-way ANOVA with repeated measures (betweensubjects factor of DHEA or saline; within-subjects factor of days) was employed to examine the effect of DHEA administration on active lever presses for the self-administration of cocaine or sucrose. The Student-NewmanKeuls post hoc test was used to determine days on which the treatment groups differed. The effect of DHEA administration on the cocaine dose-response was analyzed by a twoway ANOVA (two between-subject factors, cocaine dose
$(1,0.5,0)$ and DHEA treatment (DHEA, vehicle)). Data are presented as mean \pm SEM. Results were considered significantly different if $p<0.05$.

\section{RESULTS}

\section{Effect of DHEA Treatment on Maintenance of Cocaine Self-Administration}

After 14-16 consecutive days of cocaine self-administration ( $1 \mathrm{mg} / \mathrm{kg} /$ infusion), rats achieved maintenance of cocaine self-administration ( $\geqslant 3$ days of $15-25$ lever presses for cocaine reinforcement; $<20 \%$ deviation from the mean). There were no significant differences in active lever presses and reinforcements between the group to be treated with DHEA and the group to be treated with vehicle. Once maintenance was achieved, rats received daily i.p. injections of either DHEA $(2 \mathrm{mg} / \mathrm{kg})$ or vehicle $90 \mathrm{~min}$ before being allowed to self-administer cocaine. In the DHEA-treated rats, there was a gradual decrease in the number of active lever responses, with 19 days needed to lower the number to about $6 / \mathrm{h}$ (Figure 1a). In rats receiving daily injections of vehicle instead of DHEA, both the number of active lever responses and cocaine reinforcements remained stable (Figure 1b). A one-way ANOVA with repeated measures for the active lever responses revealed a main effect of DHEA treatment (F $(1,21)=8.2 ; p<0.01)$, days $(\mathrm{F}(20,420)=4.8 ; p<0.001)$, and an interaction of treatment by days $(\mathrm{F}(20,420)=4.57 ; p<0.001)$. For number of reinforcements, there was a main effect of DHEA treatment $(F(1,21)=25.55 ; p<0.001)$, day $(F(20,420)=3.97$; $p<0.001)$, and an interaction of treatment by days $(\mathrm{F}(20,420)=10.63 ; p<0.001)$. There was no change in the number of inactive lever responses during the experiment (data not shown).

Vehicle-treated rats that achieved stable maintenance levels throughout the experiment, and rats that upon daily injections of DHEA had lowered their active lever pressing to five per session were again placed into the conditioning chambers where they were exposed to either a lower dose of cocaine $(0.5 \mathrm{mg} / \mathrm{kg} /$ lever press $)$ or no cocaine. As expected, decreasing the dose of cocaine, infused by pushing the lever, in rats that had achieved stable maintenance levels resulted in an increase in lever responses (200-500\%). In DHEA-treated rats, no significant differences were observed in their low levels of attempts to receive cocaine (Figure 1c). A two-way ANOVA analysis for the active lever responses revealed a main effect of DHEA treatment $(\mathrm{F}(1,55)=37.2 ; p<0.0001)$, a main effect of cocaine dose $(\mathrm{F}(2,55)=20.2 ; p<0.0001)$, and an interaction between treatment and cocaine dose $(\mathrm{F}(2,55)=16.3$; $p<0.0001)$. A similar effect was seen with reinforcements, where decreasing the dose of cocaine in rats that had achieved stable maintenance levels resulted in an increase in reinforcements (180-300\%).

As with the number of lever presses, no significant differences were observed in the number of reinforcements of the DHEA-treated group (Figure 1d). A two-way ANOVA analysis revealed a main effect of DHEA treatment $(\mathrm{F}(1,55)=56.7 ; p<0.0001)$, a main effect of cocaine dose $(\mathrm{F}(2,55)=18.08 ; p<0.0001)$, and an interaction between treatment and cocaine dose $(\mathrm{F}(2,55)=16.26 ; p<0.0001)$. 

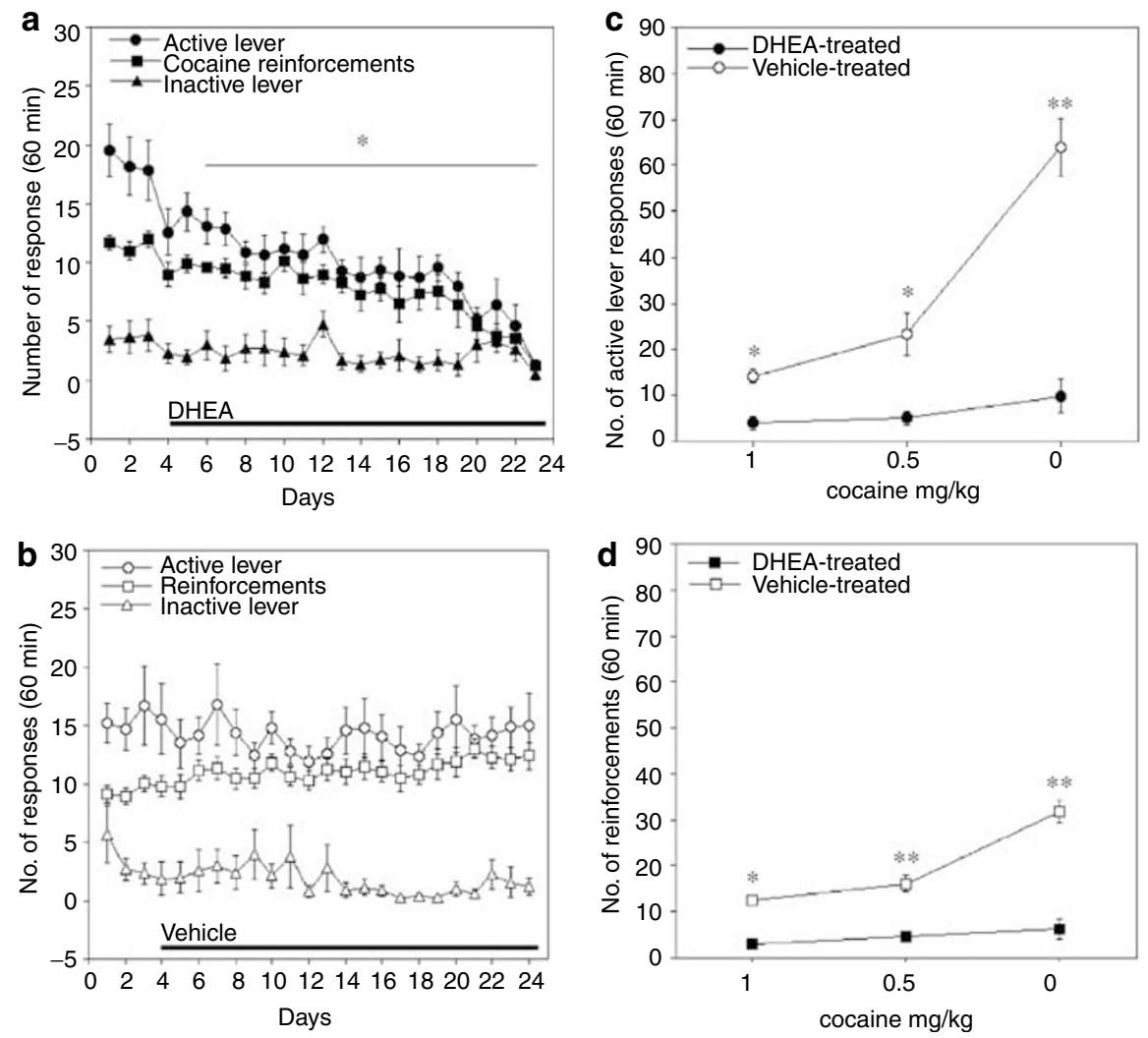

Figure I Effect of chronic DHEA treatment on self-administration of cocaine. Rats that reached maintenance upon self-administration of cocaine received a daily injection of DHEA ( $2 \mathrm{mg} / \mathrm{kg} ; n=9$; panel a) or a vehicle $(n=13$; panel b) 90 min prior to placement in the conditioning chamber. Last 3 days of maintenance before injection of DHEA or vehicle are included. After 19 days of treatment (day 23), rats of both groups were allowed to self-administer a lower dose of cocaine (panels $\mathrm{c}$ and $\mathrm{d}$, respectively). The mean \pm SEM numbers of active and inactive lever responses, and of cocaine reinforcements are presented. $* p<0.01$, main effect of DHEA treatment vs maintenance in panel a or vs vehicle-treated rats in panels $c$ and $d . * * 2<0.00 I$, main effect of treatment (Student-Newmann-Keuls post hoc test).

\section{Effect of DHEA Treatment on Reinstatement to Cocaine-Seeking Behavior}

Cocaine priming did not induce reinstatement in the DHEA-treated rats, as opposed to vehicle-treated controls (Figure 2). A two-way ANOVA analysis for the active lever responses (Figure 2a) revealed a main effect of DHEA treatment $(\mathrm{F}(1,17)=17.1 ; p<0.001)$, a main effect of cocaine reinstatement $(\mathrm{F}(1,17)=22.9 ; p<0.001)$, and an interaction between treatment and reinstatement $(\mathrm{F}(1,17)=20.4 ; p<0.001)$. Similarly, for the number of reinforcements (Figure 2b), there was a main effect of DHEA treatment $(\mathrm{F}(1,16)=21.6 ; p<0.001)$, a main effect of cocaine reinstatement $(\mathrm{F}(1,16)=27.7 ; p<0.001)$, and an interaction between treatment and cocaine relapse $(\mathrm{F}(1,16)=24.7 ; p<0.001)$. No group differences were observed for the number of sessions to reach the extinction criterion.

\section{Effect of Chronic DHEA Treatment on Maintenance of Sucrose Self-Administration}

We evaluated whether DHEA treatment disrupts general operant behavior by testing its effect on sucrose intake. Numbers of active lever responses and sucrose reinforcements remained stable before and during the 19 days of
DHEA treatment (Figure 3). A one-way ANOVA with repeated measures for the active lever responses and for the number of reinforcements found no main effect of DHEA treatment, days, and interaction of treatment by days.

\section{DISCUSSION}

A successful therapy for prevention of cocaine addiction has not yet been found (Carroll et al, 1999). The present study tested the effect of a natural neurosteroid, DHEA, on cocaine-seeking behavior using a controlled self-administration paradigm in rats.

Several days of chronic exposure to exogenous DHEA $(2 \mathrm{mg} / \mathrm{kg})$ attenuated cocaine self-administration. A longer period (19 days) of daily DHEA treatment decreased the cocaine-seeking behavior of the rats to $<20 \%$ of their maintenance levels. As indicated by decreasing the cocaine dose, DHEA does not seem to decrease cocaine selfadministration by increasing sensitization to the reinforcing effects of a dose of cocaine.

The effect of DHEA on cocaine-induced reinstatement of drug seeking in rats exposed to extinction conditions was also examined. Rats receiving DHEA $(2 \mathrm{mg} / \mathrm{kg}$ ) daily showed a minimal response to acute priming with cocaine, 

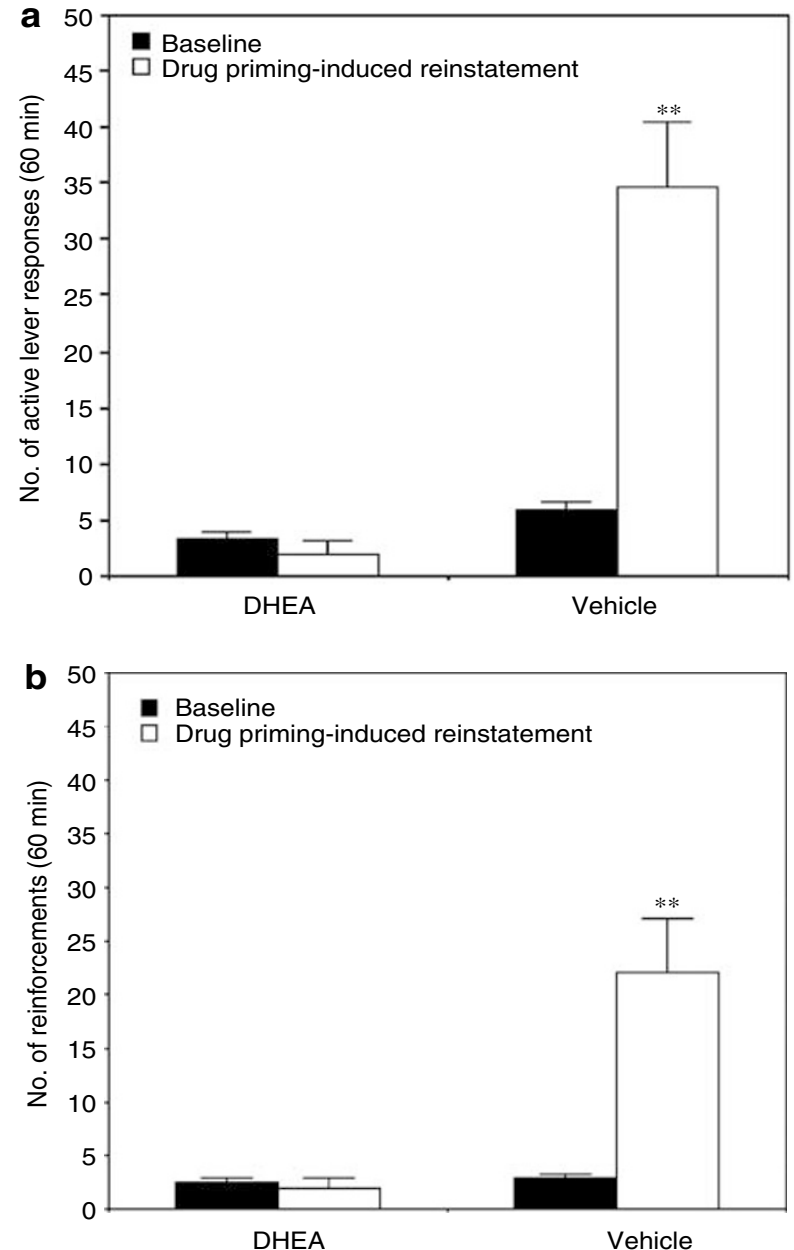

Figure 2 Effect of chronic DHEA treatment on relapse to cocaineseeking behavior. Upon extinction of cocaine-seeking behavior, a priming injection of cocaine $(10 \mathrm{mg} / \mathrm{kg}$, i.p.) was administered $10 \mathrm{~min}$ before placement in the conditioning chambers. The mean \pm SEM numbers of (a) active lever responses and (b) reinforcements are presented. $* * * 0.001$ vs its corresponding baseline and vs DHEA treatment (StudentNewmann-Keuls post hoc test).

which suggests that DHEA can protect against relapse to cocaine usage following re-exposure to the drug. It will be interesting to further examine the effect of DHEA treatment in other models of reinstatement such as cue and stress.

No surge in active lever response accompanied initiation of DHEA treatment, which would have been expected if DHEA blocked the reward effect of cocaine. This result is interesting, since most difficulties of addicts to stay on an anti-drug program occur during the first weeks, when expectation for reward is highest (Self and Choi, 2004). Indeed, when higher doses of DHEA (10-20 mg/kg) were coadministered with cocaine for a short period of time (4 days), a markedly increased cocaine-induced CPP was reported (Romieu et al, 2003).

Extinction of responding maintained by appetitive rewards has been suggested to induce multiple stress events including activation of the hypothalamus-pituitary-adrenal axis, glucocorticoid secretion, and central $\beta$-endorphin release (Vescovi et al, 1992; Shaham et al, 2003). Hence, it was previously suggested that alleviation of distress
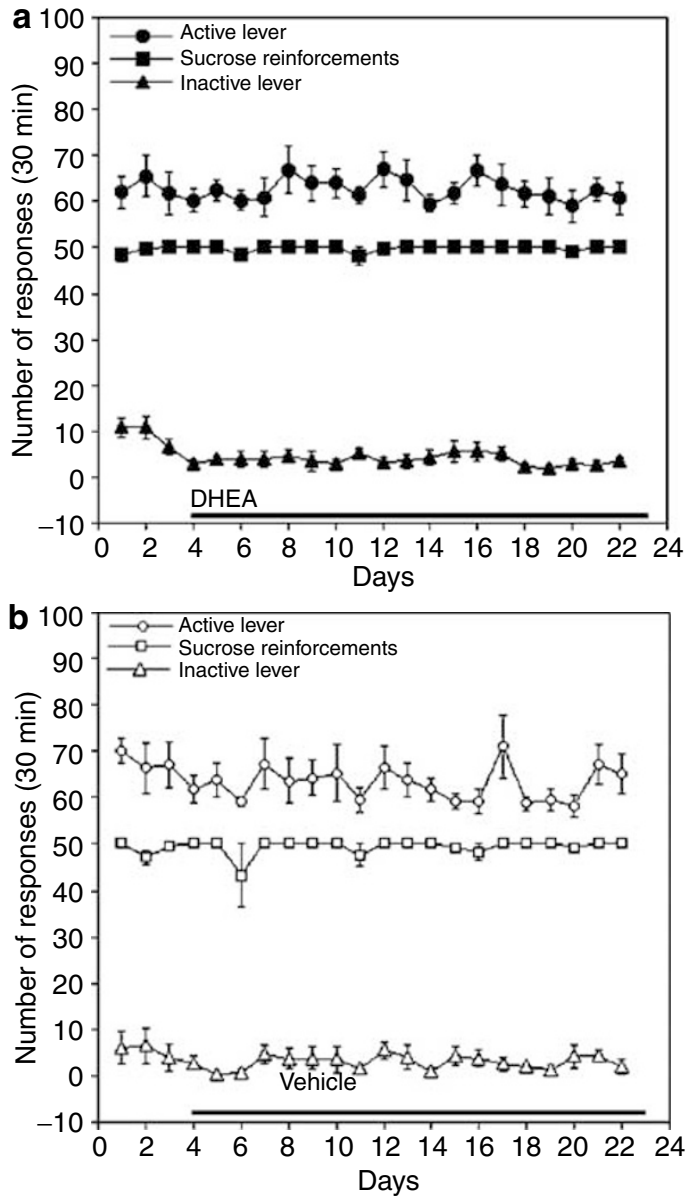

Figure 3 Effect of chronic DHEA treatment on sucrose self-administration. Rats that reached maintenance upon self-administration of sucrose received a daily injection of DHEA ( $2 \mathrm{mg} / \mathrm{kg} ; n=6$; panel a) or a vehicle $(n=4$; panel b) $90 \mathrm{~min}$ prior to placement in the conditioning chamber. Last 3 days of maintenance before injection of DHEA or vehicle are included. The mean \pm SEM numbers of active and inactive lever responses, and of sucrose reinforcements are presented.

associated with cocaine withdrawal may facilitate achieving abstinence (Self and Choi, 2004; Wilkins et al, 2005). Furthermore, during withdrawal, cocaine addicts have high plasma cortisol levels, which peak 6 days after initiation of the withdrawal and then gradually decrease (BuydensBranchey et al, 2002). As the levels of plasma cortisol decrease, the levels of DHEA-S gradually increase. Only patients in which a spontaneous increase in DHEA-S levels was observed were identified as being successful at abstaining from cocaine usage over time (Wilkins et al, 2005). Although a connection between DHEA/DHEA-S, low distressed mood levels, and enhanced CNS resiliency during withdrawal was suggested (Wilkins et al, 2005), it seems that selecting their exogenous dose is critical to avoid relapse (Shoptaw et al, 2004).

The effect of exogenously applied DHEA $(2 \mathrm{mg} / \mathrm{kg})$ on cocaine-seeking behavior may be due to its conversion to DHEA-S in the serum and brain (Maayan et al, 2005), in addition to increases in other bioactive neurosteroids (Dubrovsky, 2005). These neurosteroids may interact with various neurosystems involved in mood and drugseeking behaviors, such as glutamatergic, GABAergic, and 
dopaminergic systems. Since DHEA can function as an antidepressant in both animals and humans (Maayan et al, 2005; Wolkowitz et al, 1997), it may lower distress involved with cocaine withdrawal (Self and Choi, 2004), similar to the $\beta$-endorphin-induced lowering of frustration during extinction (Roth-Deri et al, 2003, 2004).

An additional possible mechanism for the DHEA-induced attenuation of cocaine-seeking behavior suggests the involvement of sigma-1 receptors. The sigma- 1 receptor is critically involved in the rewarding effect of cocaine, as was shown using the CPP (Romieu et al, 2003, 2001). Based on data indicating that DHEA acts as an agonist of these receptors (Maurice et al, 1999), it is possible that long administration of DHEA downregulates sigma-1 receptors as a compensatory neuroadaptation that leads to attenuation of cocaine-seeking behavior.

Even though the precise mechanism by which DHEA facilitates abrogation of cocaine-seeking behavior is not yet known, the potential of DHEA for facilitating rehabilitation of cocaine addicts is promising.

\section{ACKNOWLEDGEMENTS}

This study was supported in part by a grant from the Israel Science Foundation and from the Israel Anti-Drug Authority to GY. The research reported in this paper was completed as part of the first author's $\mathrm{PhD}$ dissertation, in the Faculty of Life Sciences, Bar-Ilan University, Ramat-Gan, Israel.

\section{REFERENCES}

Buydens-Branchey L, Branchey M, Hudson J, Dorota MM (2002). Perturbations of plasma cortisol and DHEA-S following discontinuation of cocaine use in cocaine addicts. Psychoneuroendocrinology 27: 83-97.

Carroll FI, Howell LL, Kuhar MJ (1999). Pharmacotherapies for treatment of cocaine abuse: preclinical aspects. J Med Chem 42: 2721-2736.

Corpechot C, Young J, Calvel M, Wehrey C, Veltz JN, Touyer G et al (1993). Neurosteroids: 3 alpha-hydroxy-5 alpha-pregnan20-one and its precursors in the brain, plasma, and steroidogenic glands of male and female rats. Endocrinology 133: 1003-1009.

Dubrovsky BO (2005). Steroids, neuroactive steroids and neurosteroids in psychopathology. Prog Neuropsychopharmacol Biol Psychiatry 29: 169-192.

Falkenstein E, Tillmann HC, Christ M, Feuring M, Wehling M (2000). Multiple actions of steroid hormones - a focus on rapid, nongenomic effects. Pharmacol Rev 52: 513-556.

Jung-Testas I, Hu ZY, Baulieu EE, Robel P (1989). Steroid synthesis in rat brain cell cultures. J Steroid Biochem 34: 511-519.

Kaminski RM, Gasior M, Carter RB, Witkin JM (2003). Protective efficacy of neuroactive steroids against cocaine kindled-seizures in mice. Eur J Pharmacol 474: 217-222.

Maayan R, Morad O, Dorfman P, Overstreet DH, Weizman A, Yadid G (2005). The involvement of dehydroepiandrosterone
(DHEA) and its sulfate ester (DHEAS) in blocking the therapeutic effect of electroconvulsive shocks in an animal model of depression. Eur Neuropsychopharmacol 15: 253-262.

Maurice T, Phan VL, Urani A, Kamei H, Noda Y, Nabeshima T (1999). Neuroactive neurosteroids as endogenous effectors for the sigmal (sigma1) receptor: pharmacological evidence and therapeutic opportunities. Jpn J Pharmacol 81: 125-155.

Reddy DS, Kulkarni SK (1997). Reversal of benzodiazepine inverse agonist FG 7142-induced anxiety syndrome by neurosteroids in mice. Methods Find Exp Clin Pharmacol 19: 665-681.

Romieu P, Meunier J, Garcia D, Zozime N, Martin-Fardon R, Bowen WD et al (2001). The sigma 1 (sigma1) receptor activation is a key step for the reactivation of cocaine conditioned place preference by drug priming. Psychopharmacology (Berl) 175: 154-162.

Romieu P, Martin-Fardon R, Bowen WD, Maurice T (2003). Sigma 1 receptor-related neuroactive steroids modulate cocaineinduced reward. J Neurosci 23: 3572-3576.

Roth-Deri I, Schindler CJ, Yadid G (2004). A critical role for beta-endorphin in cocaine-seeking behavior. NeuroReport 15: 519-521.

Roth-Deri I, Zangen A, Aleli M, Goelman RG, Pelled G, Nakash R et al (2003). Effect of experimenter-delivered and self-administered cocaine on extracellular beta-endorphin levels in the nucleus accumbens. J Neurochem 84: 930-938.

Self DW, Choi KH (2004). Extinction-induced neuroplasticity attenuates stress-induced cocaine seeking: a state-dependent learning hypothesis. Stress 7: 145-155.

Shaham Y, Shalev U, Lu L, De Wit H, Stewart J (2003). The reinstatement model of drug relapse: history, methodology and major findings. Psychopharmacology (Berl) 168: 3-20.

Shoptaw S, Majewska MD, Wilkins J, Twitchell G, Yang X, Ling W (2004). Participants receiving dehydroepiandrosterone during treatment for cocaine dependence show high rates of cocaine use in a placebo-controlled pilot study. Exp Clin Psychopharmacol 12: $126-135$.

Soares BG, Lima MS, Reisser AA, Farrell M (2003). Dopamine agonists for cocaine dependence. Cochrane Database Syst Rev, CD003352.

Stephen TH, Jonathan LK (1998). Cocaine Abuse Behavior, Pharmacology, and Clinical Applications. Academic Press: New York.

Vanover KE, Suruki M, Huber M, Wilent WB, Carter RB (2000). Neuroactive steroids attenuate cocaine-induced sucrose intake in rats, but not cocaine-induced hyperactivity in mice. Psychopharmacology (Berl) 149: 269-276.

Vescovi PP, Coiro V, Volpi R, Passeri M (1992). Diurnal variations in plasma ACTH, cortisol and beta-endorphin levels in cocaine addicts. Horm Res 37: 221-224.

Wilkins JN, Majewska MD, Van Gorp W, Li SH, Hinken C, Plotkin D et al (2005). DHEAS and POMS measures identify cocaine dependence treatment outcome. Psychoneuroendocrinology 30: $18-28$.

Wilkins J, van Gorp W, Hinken C, Welch B, Wheatley A, Plotkin D et al (1997). Relaps to cocaine use may be predicted in early abstinence by low plasma dehydroepiandrosterone levels. NIDA Res Mongr Ser 174: 183.

Wolkowitz OM, Reus VI, Roberts E, Manfredi F, Chan T, Raum WJ et al (1997). Dehydroepiandrosterone (DHEA) treatment of depression. Biol Psychiatry 41: 311-318. 